\title{
BMJ Global Health Barriers to maternal health services during the Ebola outbreak in three West African countries: a literature review
}

\author{
Piper Yerger, ${ }^{1,2}$ Mohamed Jalloh, ${ }^{3}$ Cordelia E M Coltart, ${ }^{1}$ Carina King (D) ${ }^{1,3}$
}

To cite: Yerger $P$, Jalloh $M$, Coltart CEM, et al. Barriers to maternal health services during the Ebola outbreak in three West African countries: a literature review. BMJ Global Health 2020;5:e002974. doi:10.1136/ bmjgh-2020-002974

Handling editor Seye Abimbola

- Additional material is published online only. To view, please visit the journal online (http://dx.doi.org/10.1136/ bmjgh-2020-002974).

Received 26 May 2020 Revised 22 July 2020 Accepted 25 July 2020

Check for updates

(C) Author(s) (or their employer(s)) 2020. Re-use permitted under CC BY-NC. No commercial re-use. See rights and permissions. Published by BMJ.

1 Institute for Global Health, University College London, London, UK

${ }^{2}$ Care Ring, Children and Family Services Center, Charlotte, North Carolina, USA

${ }^{3}$ Department of Global Public Health, Karolinska Institutet, Stockholm, Sweden

Correspondence to

Dr Carina King;

c.king@ucl.ac.uk

\section{ABSTRACT}

Introduction The Ebola virus disease (EVD) outbreak in West Africa, affecting Guinea, Liberia and Sierra Leone from 2014 to 2016, was a substantial public health crisis with health impacts extending past EVD itself. Access to maternal health services (MHS) was disrupted during the epidemic, with reductions in antenatal care, facility-based deliveries and postnatal care. We aimed to identify and describe barriers related to the uptake and provision of MHS during the 2014-2016 EVD outbreak in West Africa. Methods In June 2020, we conducted a scoping review of peer-reviewed publications and grey literature from relevant stakeholder organisations. Search terms were generated to identify literature that explained underlying access barriers to MHS. Published literature in scientific journals was first searched and extracted from PubMed and Web of Science databases for the period between 1 January 2014 and 27 June 2020. We hand-searched relevant stakeholder websites. A 'snowball' approach was used to identify relevant sources uncaptured in the systematic search. The identified literature was examined to synthesise themes using an existing framework.

Results Nineteen papers were included, with 26 barriers to MHS uptake and provision identified. Three themes emerged: (1) fear and mistrust, (2) health system and service constraints, and (3) poor communication. Our analysis of the literature indicates that fear, experienced by both service users and providers, was the most recurring barrier to MHS. Constrained health systems negatively impacted MHS on the supply side. Poor communication and inadequately coordinated training efforts disallowed competent provision of MHS.

Conclusions Barriers to accessing MHS during the EVD outbreak in West Africa were influenced by complex but inter-related factors at the individual, interpersonal, health system and international level. Future responses to EVD outbreaks need to address underlying reasons for fear and mistrust between patients and providers, and ensure MHS are adequately equipped both routinely and during crises.

\section{INTRODUCTION}

Timely access to skilled maternal health services (MHS) is a critical component of precluding preventable maternal morbidity and mortality. ${ }^{1}$ Although maternal mortality decreased 29\% globally between 1990 and

\section{Key questions}

What is already known?

- Prior evidence from the 2014 to 2016 outbreak of Ebola virus disease (EVD) in Guinea, Liberia and Sierra Leone depicts a deterioration in access to maternal health services (MHS).

What are the new findings?

- Fear and mistrust were significant barriers to both utilisation and provision of MHS.

- Existing healthcare resource scarcity was exacerbated during the EVD outbreak.

- Infection control policies impeded provision of MHS and reinforced mistrust between patients and healthcare workers (HCWs)

- Education to HCWs and communities regarding EVD was insufficient.

What do the new findings imply?

- Patient-provider fear and mistrust should be addressed through policy and educational interventions during future EVD outbreaks.

- Health systems should be equipped to continue routine services during EVD outbreaks.

- Prompt education and training to HCWs and communities is necessary to facilitate continued access to MHS.

2015, the extent to which Millennium Development Goal 5 aimed to reduce maternal morbidity and mortality was broadly missed. ${ }^{2}$ Continued efforts are essential to improve equitable access to MHS, particularly in the context of public health crises. Public health crises, such as the 2014 outbreak of Ebola virus disease (EVD) in West Africa, risk disrupting MHS and progress made in maternal health outcomes, particularly in regions with weak existing health infrastructure. ${ }^{3}$

There is evidence from the 2014 outbreak of EVD in Guinea, Liberia and Sierra Leone that shows a deterioration in uptake and provision of MHS, ${ }^{4-10}$ while just two studies, both conducted in Sierra Leone, reported insignificant changes in access to MHS. ${ }^{11} 12$ When compared with preoutbreak metrics, 
significant reductions in facility-based deliveries have been found across the three countries. ${ }^{4-10}$ Similarly, across Guinea, Liberia and Sierra Leone, reported utilisation of antenatal care (ANC) and postnatal care (PNC) saw significant reductions. ${ }^{5-10}$ Previous studies have estimated that utilisation of the first ANC visit and facilitybased deliveries in Guinea and PNC in Sierra Leone were found to be reduced by $59 \%, 62 \%{ }^{6}$ and $22 \%,{ }^{13}$ respectively. In parts of Liberia, another study reported utilisation of ANC and facility-based deliveries to be at less than $14 \%$ and $9 \%$ of peak utilisation, respectively. ${ }^{5}$ After the start of the outbreak, one paper reports a $34 \%$ increase in the facility-based maternal mortality ratio in Sierra Leone ${ }^{13}$ with other authors estimating similar increases in maternal mortality due to reduced access to MHS. ${ }^{8}$

Prior studies that quantified the negative impact of EVD on access to MHS did not robustly provide an explanation for the documented reductions. ${ }^{4-10}$ With more frequent EVD outbreaks occurring since 2014, as seen in the Democratic Republic of Congo, it is essential to quantify negative changes in MHS, and investigate the underlying causes of the negative changes to inform policies and interventions. Against this background, we aimed to identify and describe barriers to MHS uptake and provision during the 2014-2016 EVD outbreak in Guinea, Liberia and Sierra Leone to guide recommendations for future EVD outbreak responses.

\section{METHODS}

We conducted a scoping literature review using scholarly and grey literature.

\section{Search method}

We searched PubMed and Web of Science in August 2019, and updated this in June 2020. Search terms input to 'All Fields' were: ebola OR 'ebola virus' OR 'ebola virus disease' AND matern* OR obstet* OR perinatal OR antenatal OR pregnan* OR birth* OR 'child birth' AND health OR 'health care' OR service* OR deliver* OR provi* OR utili!e* OR uptake OR system* OR impact* OR implication* OR barrier* OR facilit* OR access* OR 'care seeking'.

Grey literature not published in scientific journals was included to consider research from key actors in the EVD response. To facilitate inclusivity, a broad search strategy was employed using the phrase 'Ebola and maternal health' on websites of the following key response actors during the outbreak: WHO, Médecins Sans Frontières, Oxfam, United Nations Population Fund (UNFPA), UNICEF, Centers for Disease Control and Prevention, and the Ministries of Health for Liberia, Guinea and Sierra Leone. We performed a hand-search, or 'snowball technique', using the references of literature included, and relevant literature reviews, to identify any further sources uncaptured in the systematic search.

\section{Patient and public involvement}

Neither patients nor individuals of the public were involved in our research at any stage.

\section{Inclusion and exclusion}

All literature generated was screened by title, abstract and full text using inclusion and exclusion criteria. We included literature that provided an explanation of the underlying barriers to accessing MHS. Specific inclusion criteria comprised literature in English or French, set in Guinea, Liberia and/or Sierra Leone, regarding EVD, published between 1 January 2014 and 27 June 2020 and relating to MHS, users or providers. MHS included health services necessary to promote health, manage complications and prevent morbidity and mortality related to pregnancy, birth and the postpartum period, including skilled birth attendance, ANC and PNC. ${ }^{14}$

We excluded vaccine research, development and clinical trials; clinical management, pathological and physiological research; case studies and case definitions; chain of transmission and outbreak modelling; capacity building, systems strengthening and strategic planning for future outbreaks; assessments of the status of MHS before or after the epidemic; ethics papers; personal commentary; child health, including prevention of mother-to-child transmission of HIV; press releases and news articles; and reviews, reflections and analyses of existing literature.

\section{Analysis and data extraction}

An existing theoretical framework was applied to guide literature analysis. ${ }^{15}$ The framework's authors expanded on existing literature regarding barriers to accessing healthcare in low-income countries. ${ }^{15-17}$ The following definition of access was used:

The opportunity to reach and obtain appropriate health care services in situations of perceived need for care... resulting from the interface between the characteristics of persons, households, social and physical environments and the characteristics of health systems, organisations and providers. ${ }^{18}$

The authors described barriers to access in four categories: geographic accessibility, availability, affordability and acceptability. ${ }^{15}$ Each category is dichotomised further into supply side (service provision) and demand side (service uptake) barriers. ${ }^{15}$ Barriers to service provision considered elements at the health system level that hampered the ability or desire of providers to deliver MHS competently and safely. ${ }^{15}$ Barriers to service uptake hindered users from seeking or receiving MHS. ${ }^{15}$

\section{RESULTS}

Database searches yielded 454 papers, of which 166 were duplicates. The remaining 288 papers were screened and excluded by title $(n=237)$, abstract $(n=24)$ and full text $(\mathrm{n}=11)$, resulting in 16 papers. Hand-searching resulted in an additional three papers included (figure 1; online supplemental material 1). Reasons for exclusions following abstract review included: papers unrelated to MHS ( $n=5)$; assessments of MHS before or after the EVD outbreak $(n=2)$; capacity building or systems strengthening focus $(n=2)$; papers that quantified access to MHS 


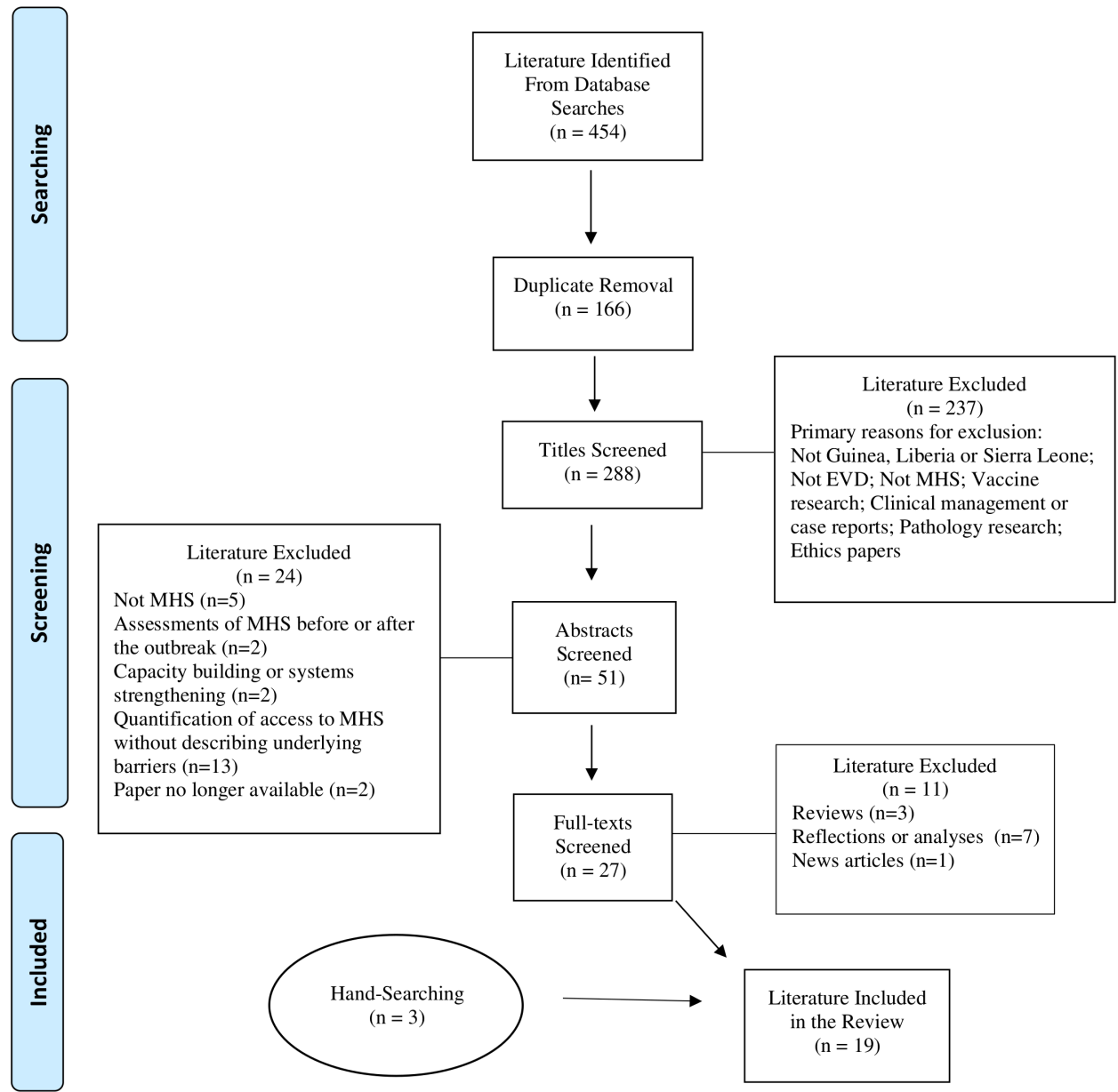

Figure 1 Preferred Reporting Items for Systematic Reviews and Meta-Analyses (PRISMA) flow diagram. EVD, Ebola virus disease; MHS, maternal health services.

without describing underlying barriers $(\mathrm{n}=13)$; or papers no longer available $(n=2)$. Exclusions following full-text reading were reviews $(n=3)$, reflections or analyses $(n=7)$ and one news article. Of the 19 papers included, 15 were explicitly peer reviewed and four did not clearly state the peer-review status. The types of literature included were: four quantitative studies, five qualitative studies, eight mixed methods studies, one academic commentary and one modelling study. Two papers were specific to Guinea, 4 to Liberia, 11 to Sierra Leone and 2 were general to all three countries. A Preferred Reporting Items for Systematic Reviews and Meta-Analyses diagram illustrates the results of the literature search (figure 1). ${ }^{19}$

After applying the framework, ${ }^{15} 26$ barriers to MHS uptake and provision were identified and are presented in table 1.

The literature indicates that accessible, available, affordable and acceptable MHS diminished during the EVD outbreak, with availability and acceptability particularly affected. Patterns in the literature yielded three themes: fear and mistrust; health system and service constraints; and poor communication. Each theme represents a synthesis of barriers to MHS for both uptake and provision as reflected in the literature, and particularly concurs with the research of Bell and colleagues. ${ }^{20}$

\section{Theme l: fear and mistrust}

Fifteen papers reported fear and mistrust as barriers to MHS uptake and/or provision. Three papers made no mention of fear or mistrust as a barrier to MHS, ${ }^{132122}$ while another recognised fear among healthcare workers (HCWs) that did not impede service provision. ${ }^{23}$

Multidimensional fear cut across every dimension of the healthcare access framework and was experienced by MHS users and providers in Guinea, Liberia and Sierra Leone. The literature evidenced that pregnant women feared multiple aspects of engaging with healthcare: acquiring EVD at health facilities; being transferred to an EVD treatment centre; the appearance of HCWs in personal protective equipment (PPE); receiving disrespectful care; and the possible refusal of MHS. ${ }^{324-35}$ Fear and stigmatisation of HCWs was a particularly noteworthy barrier to MHS given their increased exposure to and risk of contracting EVD. ${ }^{34}{ }^{26-31}{ }^{35}$ Demand-side fear had immediate subsidiary effects as it led to delayed uptake of MHS, which increased acuity of maternal morbidity. ${ }^{24} 2630$

Fear was facilitated by existing public mistrust of the government and government-backed healthcare and was exacerbated as rumours regarding EVD and the intentions of HCWs and other EVD responders proliferated. $^{324-30} 3235$ Authors reported rumours such as HCWs 
Table 1 Barriers to uptake and provision of maternal health services

\begin{tabular}{|c|c|}
\hline Provision barriers & Uptake barriers \\
\hline \multicolumn{2}{|l|}{ Geographic accessibility } \\
\hline $\begin{array}{l}\text { Travel restrictions } \\
\text { - Lack of ambulances } \\
\text { L } 30\end{array}$ & - Quarantine and travel restrictions ${ }^{33} 35$ \\
\hline \multicolumn{2}{|l|}{ Availability } \\
\hline 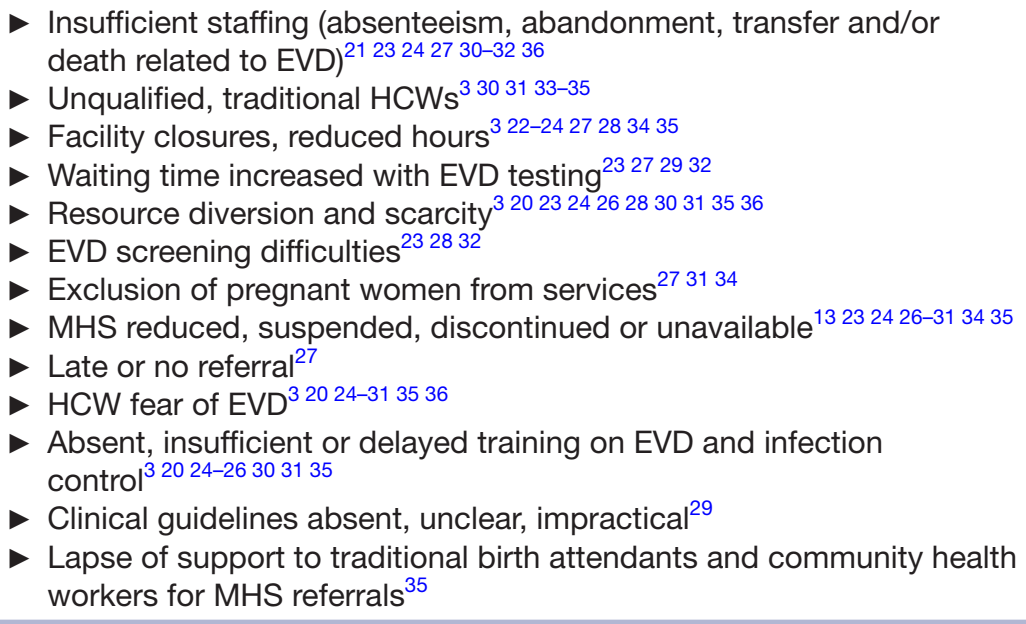 & $\begin{array}{l}\text { Rumours regarding EVD and the intentions of } \\
\text { HCWs and other EVD responders }\end{array}$ \\
\hline \multicolumn{2}{|l|}{ Affordability } \\
\hline \multicolumn{2}{|l|}{$\begin{array}{l}\text { Informal fees }{ }^{31} \\
\text { Shift from public to private facilities due to fear of EVD in the public } \\
\text { sector }^{3}\end{array}$} \\
\hline \multicolumn{2}{|l|}{ Acceptability } \\
\hline $\begin{array}{l}\text { Rumours that MHS are no longer free } \\
\text { - Staff mistrust of pregnant women } \\
\text { Worsened interpersonal skills among HCWs }\end{array}$ & $\begin{array}{l}\text { Community fear and/or mistrust of facility-based } \\
\text { HCWs and health facilities }{ }^{34-28 ~ 30-36} \\
\text { Preference for/increased traditional, community- } \\
\text { based care }{ }^{330} 3133-35 \\
\text { Stigmatisation of HCWs, pregnant women and } \\
\text { EVD } 24293133 \\
\text { - No touch policy }\end{array}$ \\
\hline
\end{tabular}

Source: Adapted theoretical framework. ${ }^{15}$

EVD, Ebola virus disease; HCW, healthcare worker; MHS, maternal health services.

injecting EVD 273032 or spreading $\mathrm{EVD}^{335}$ for money ${ }^{24} 25$ or witchcraft. ${ }^{25}$ It was further rumoured that HCWs were unnecessarily transferring patients to EVD treatment centres for money or other unknown reasons. ${ }^{25} 35$ One author reported the rumour that Liberians were being killed so that westerners could have their kidneys. ${ }^{3}$ Although the details differed, rumours acted as a barrier to MHS in all three countries. Further, in part as result of these rumours, one paper concluded that uptake of public MHS decreased, while private MHS increased, ${ }^{3}$ potentially decreasing affordability of MHS.

Across all three countries, reports found that HCWs providing MHS feared acquiring EVD from patients and transmitting it to their families or communities. ${ }^{3}$ 25-31 35 This is particularly relevant for MHS due to the heightened risk of contracting EVD from exposure to bodily fluids that are expelled during childbirth. ${ }^{27}$ This affected access from the supply side as motivation to provide MHS diminished.
While the literature suggests that mistrust was a barrier for women to seek MHS, ${ }^{3} 24252728303135$ those who did seek MHS were distrusted by HCWs. ${ }^{27}{ }^{31}$ In Sierra Leone, UNFPA reported that HCWs distrusted pregnant women to be honest about EVD symptoms or exposure, reducing acceptable provision of MHS. ${ }^{27}$ This fearful attitude towards pregnant women was seemingly embodied by the community as well. ${ }^{31}$ In Liberia, pregnant women claimed to be the 'most feared social group' after experiencing stigmatisation from their communities, ${ }^{31}$ which likely reduced demand-side access to MHS.

\section{Theme II: health system and service constraints Resource diversion and scarcity}

The literature indicates that health system constraints posed a barrier to MHS. A lack of resources for MHS such as equipment, drugs, supplies, personnel and, most critically, PPE, was reported across the three countries. ${ }^{20232628303135}$ Existing resource scarcity was 
exacerbated during the epidemic as resources were diverted away from routine MHS to supplement the EVD response. ${ }^{26}{ }^{30}{ }^{35}$ In Liberia, Bell et al linked lack of PPE to fear of service provision. ${ }^{20}$

\section{Health facilities and personnel}

Health facility closure and reduced health facility hours were reported in Guinea, Liberia and Sierra Leone. ${ }^{322-24} 283435$ Three papers, two in Sierra Leone ${ }^{22} 23$ and one in Guinea, ${ }^{24}$ reported the closure of fewer public health facilities compared with private health facilities, while just one study conducted in Liberia reported the inverse. ${ }^{3}$ In Sierra Leone, Drevin et al reported that closure of private health facilities increased the burden of demand for caesarean sections in the public sector. ${ }^{23}$ Even when facilities remained open, quarantines and travel restrictions, imposed to facilitate EVD control, worsened geographic accessibility to MHS for both service users and some non-governmental organisation (NGO)-staffed providers. ${ }^{33} 35$

Insufficient numbers of HCWs also posed a barrier to available MHS in the three countries. HCW shortages during the outbreak were attributed to job abandonment, transfer of HCWs to EVD treatment centres and HCW death from EVD. ${ }^{21} 2324273036$ A modelling study postulates increases in maternal mortality of $38 \%, 74 \%$ and $111 \%$ in Guinea, Sierra Leone and Liberia, respectively, due to EVD-related HCW death. ${ }^{21}$ Some HCWs abandoned their work due to fear of acquiring EVD from pregnant and labouring women. ${ }^{27}$ Among the HCWs that continued service provision, it was reported that some refused care to pregnant women, halting availability of MHS in some areas. ${ }^{2734}$

Financial barriers to MHS were addressed in three papers. On the demand side, research led by UNFPA in Sierra Leone reported rumours that previously free health services, including MHS, were no longer free during the EVD outbreak. ${ }^{27}$ In Liberia, one paper reported that informal fees in the public sector, a barrier to MHS that existed before the EVD outbreak, were exacerbated during the outbreak. ${ }^{31}$ On the supply side, it was reported in one paper that some community health workers that provided MHS were not paid during the outbreak. $^{35}$

In Liberia and Sierra Leone, the HCW gap in MHS was partially filled by traditional birth attendants (TBAs). ${ }^{3} 31$ 33-35 The literature suggests that TBAs were more trusted by pregnant women ${ }^{30} 335$ and less likely to discontinue their provision of MHS due to fear. ${ }^{35}$ However, while the Liberian Ministry of Health recognises TBAs, community-based births are normally forbidden and referral to facilities is mandatory. ${ }^{35}$ This policy was not enforced during the outbreak, which reduced skilled, facility-based MHS. ${ }^{355}$ Because TBAs were not authorised to attend childbirths, they lacked the necessary resources for births and training needed for EVD infection control and prevention (ICP). ${ }^{35}$

\section{No touch policy}

As EVD is transmitted via bodily contact with infected individuals, a strict 'no touch' policy was enacted in health systems across Guinea, Liberia and Sierra Leone, which posed a barrier to MHS. ${ }^{27} 3135$ It was reported that HCWs in some contexts did not touch patients until proven EVD negative ${ }^{232729}$ The symptoms of EVD often mimic those of obstetric emergencies, and EVD triage and screening processes were inefficient. ${ }^{2932}$ One study in Sierra Leone reported that the difficult differential diagnosis caused pregnant women to wait in an EVD treatment centre until proven EVD negative before they were transferred to the maternity unit. ${ }^{29}$ This increased waiting times for MHS, delayed responses to obstetric emergencies and risked mortality for the pregnant woman and her fetus. ${ }^{23} 272932$ Further, Miller et al reported that HCW confusion regarding the 'no touch' policy caused the cessation of MHS in some parts of Liberia. ${ }^{35}$

\section{Theme III: poor communication}

The literature indicates that the EVD response and the ability to continue routine MHS was hampered by poor communication and coordination at the community, health system, national and international levels. ${ }^{26} 303135$ As discussed, rumours and misinformation at the community level caused barriers to using MHS, which one paper attributed to lack of or delayed community sensitisation around EVD. ${ }^{35}$ At the health system level, lack of knowledge and absent or delayed training on EVD and ICP measures were particularly highlighted as barriers to MHS. ${ }^{32024-263031}$ In Sierra Leone, some midwives received their information about EVD from informal sources, rather than reliable national or international governmental or NGOs, which risked the spread of inaccurate information and potentially increased fear. ${ }^{30}$ Midwives also reported a lack of communication on clinical guidelines for EVD-positive pregnant women. ${ }^{29}$ Even when evidence-based information was available and accessible, infection control policies and HCW confusion around or inability to implement these policies prevented provision of the necessary level of care that MHS require, which posed supply-side and demand-side barriers to MHS. ${ }^{29}$

\section{DISCUSSION}

This review explored the barriers to MHS uptake and provision during the EVD outbreak in Guinea, Liberia and Sierra Leone by applying an established healthcare access framework. We identified cross-cutting themes on barriers to MHS uptake and provision. The three recurring themes were: fear and mistrust, health system and service constraints, and poor communication. The negative impacts of fear, constrained health systems and poor communication during the EVD outbreak in West Africa have been discussed by other authors. ${ }^{37-40}$ Our analysis of the literature revealed that fear, experienced by both service users and providers, was the most recurring barrier to MHS across the region. Further, in agreeance 
with Bell et al, our analysis indicates that fear was a driver for other barriers to MHS. ${ }^{20}$ Constrained health system resources negatively impacted MHS provision. Poorly delivered communication and inadequate training efforts disallowed competent provision of MHS.

Fear played an indelible role in influencing behaviours among the public and HCWs during the EVD outbreak in West Africa. ${ }^{374}$ A consequential effect of fear was the mistrust it propagated between the public and HCWs. Moreover, it has been documented that HCWs were heavily stigmatised partly due to their high incidence of EVD infection. ${ }^{40}{ }^{42-45}$ HCWs in Guinea, Liberia and Sierra Leone had 21-32 times more risk of contracting EVD when compared with non-HCWs. ${ }^{46}$ Further, HCWs experienced EVD-related mortality rates of $1.45 \%, 8.07 \%$ and $6.85 \%$ in Guinea, Liberia and Sierra Leone, respectively. ${ }^{21}$ Considering the significant risk of morbidity that HCWs encountered provides context to demand-side fear of HCWs and health facilities as well as supply-side fear of continuing service provision.

A key aspect of the EVD response was to institute stringent protocols for ICP within health facilities, including the no touch policy and enhancements in the use of PPE by HCWs and front-line responders. ${ }^{45}$ 47-49 These protocols may have introduced some unintended consequences as the outbreak progressed. For instance, a qualitative study conducted in Sierra Leone near the end of the outbreak found that the PPE worn by health workers facilitated a breakdown in trust between patients and providers. ${ }^{40}$ Moreover, some ICP policies were costly violations of cultural norms, seemed to deepen mistrust between communities, patients and HCWs, and further facilitated opposition towards government-backed healthcare, which subsequently reduced demand-side access to facility-based MHS. ${ }^{3150-52}$ In other cases where mistrust was not a factor, some women may opt out of a facility-based delivery for practical reasons under the assumption that HCWs would not touch them. Even as the outbreak was nearing its end, lingering fear may have also influenced health-seeking behaviours. For example, a national household survey in Sierra Leone showed that only $63 \%$ of respondents were willing to ride in an ambulance if they became ill. ${ }^{53}$

Lack of PPE for HCWs was particularly highlighted in the literature as a supply-side barrier to MHS. Preoutbreak resource scarcity may have been less important or recognised by HCWs outside times of public health crisis as fear of EVD flourished. HCWs must be equipped with sufficient resources, particularly PPE, to protect themselves from infection, mitigate fear and increase provision of MHS. Further, it is important to simultaneously educate the community surrounding the individual and community-level benefits of PPE to assuage any misconceptions and mistrust that PPE propagates.

Health system constraints evidenced in the literature are relatively unsurprising given the region's weak existing infrastructure. Guinea, Liberia and Sierra Leone were deficient in all six of the WHO's criteria for a successful health system: labour force, health information, technology and supplies, governance, financing and service provision prior to the outbreak ${ }^{54}$; this made it difficult for local health systems to maintain routine MHS and effectively respond to the outbreak simultaneously. It is important to bear in mind the broader effects of an epidemic and equip routine services for success. In addition to routine MHS, obstetric emergencies require prompt facility-based attention by skilled HCWs, making consistent access to these services a high priority. Horizontally strengthening the capacities of national health systems to provide universal, routine healthcare and the ability to survey and mitigate public health risks necessitates continued efforts. ${ }^{55}$

The authors reported that the EVD outbreak caused a shift from public, facility-based MHS to private facilities ${ }^{3}$ and TBAs. ${ }^{31}{ }^{33-35}$ Increased use of private facilities for MHS raises questions around equitable access and cost barriers, while the use of TBAs poses a barrier to skilled MHS. Given that some literature indicated that TBAs were more trusted than facility-based HCWs, ${ }^{30} 33$ it may be prudent to further involve TBAs in future responses to EVD outbreaks by equipping them with the training and supplies necessary to mitigate risks of infection and barriers to MHS.

Mitigating access barriers requires intersectoral collaboration at the local, national and international levels, ${ }^{15}$ including for effective and efficient responses to public health crises. Based on research conducted during the SARS epidemic, prioritising quick, widespread dissemination of health and safety information to HCWs and communities is vital. ${ }^{56}$ Messages should be accessible, simple and culturally appropriate and should rectify any known misconceptions. ${ }^{56}$ Further, involving trusted leaders, including TBAs, as the communicators of these messages could facilitate dissemination and adherence to the public health recommendations in communities. Engaging with and educating communities is essential to curb transmission of EVD and facilitate confidence and participation in the response. ${ }^{57}$ Moreover, research conducted during the outbreak of EVD further indicates that robust, well-coordinated education for HCWs decreased levels of fear ${ }^{40}$ and may also increase motivation to provide MHS during outbreaks of EVD. Further, peer support for HCWs, both in person and via social media, increased motivation and confidence in providing health services. ${ }^{40}$

Although our review was specific to the 2014 outbreak of EVD in Guinea, Liberia and Sierra Leone, the lessons learnt may have broader relevance for outbreaks which incite fear and health system disruptions. Fear of infectious diseases certainly preceded $\mathrm{EVD}^{56}$ and health systems ill prepared to manage epidemics are not unique to Guinea, Liberia and Sierra Leone. ${ }^{58}$ Indeed, the current COVID-19 pandemic has been projected to result in a significant increase in maternal mortality based on many of the same barriers. ${ }^{59}$ Therefore, it is important that historical learning is applied to mitigate the indirect 
impacts of infectious disease outbreaks, and inform the development of resilient health systems.

This paper had four key limitations. First, it considers three heterogeneous countries, Guinea, Liberia and Sierra Leone, together. We identified more literature in Sierra Leone $(n=11)$ and Liberia $(n=4)$ compared with Guinea $(n=2)$. Assessing the region as one entity prevented an in-depth analysis of each country's social, political and economic situations, which may have posed barriers to MHS. However, themes were found common across the countries suggesting shared experiences and barriers. Second, we focused on access to MHS rather than on quality of MHS. Quality is helpful to consider, as access to poor quality services could increase harm to maternal health. Third, the literature could have exaggerated results, particularly in areas with a high volume of EVD cases, as the epidemic was an emotionally charged situation. Selection bias to ensure safety of researchers during the outbreak is plausible, and data collection conducted after its end is subject to recall bias. Further, analysis of existing data, such as health facility records, relies on complete and accurate reporting, which may have been impossible during the epidemic. Research limitations may create erroneous depictions of barriers to MHS. Future research that considers more specific regional contexts and integrates quality of care into the analysis is warranted. Finally, our review did not recognise and discuss any resiliency of MHS that was described by some authors. ${ }^{11-1323}$

\section{CONCLUSION}

The 2014 EVD outbreak in West Africa created unique and exacerbated existing barriers to MHS. Patientprovider fear and mistrust, constrained health systems and insufficient attempts to communicate with HCWs and communities were the key barriers to MHS identified. Moreover, fear was seemingly the cause or effect of other barriers to MHS. The global health community, in accordance with trusted local leaders, must prioritise strategic planning to address fear, strengthen health systems to continue routine services, and better coordinate communication and education efforts to reduce barriers to MHS in future outbreaks of EVD.

\section{Acknowledgements PY would like to thank Christopher O'Brien and Ana Rodriguez for providing access to local research facilities.}

Contributors This study was designed by PY and CK. PY conducted the literature searches, data extraction and analysis. The manuscript was primarily written by PY with input from MJ, CEMC and CK. All authors read and approved the submitted manuscript.

Funding The authors have not declared a specific grant for this research from any funding agency in the public, commercial or not-for-profit sectors.

\section{Competing interests None declared.}

Patient and public involvement Patients and/or the public were not involved in the design, or conduct, or reporting, or dissemination plans of this research.

Patient consent for publication Not required.

Provenance and peer review Not commissioned; externally peer reviewed.
Data availability statement Data sharing not applicable as no data sets were generated and/or analysed for this study.

Open access This is an open access article distributed in accordance with the Creative Commons Attribution Non Commercial (CC BY-NC 4.0) license, which permits others to distribute, remix, adapt, build upon this work non-commercially, and license their derivative works on different terms, provided the original work is properly cited, appropriate credit is given, any changes made indicated, and the use is non-commercial. See: http://creativecommons.org/licenses/by-nc/4.0/.

\section{ORCID iD}

Carina King http://orcid.org/0000-0002-6885-6716

\section{REFERENCES}

1 UNICEF. Maternal and newborn health, 2016. Available: https:// www.unicef.org/health/index_maternalhealth.html [Accessed 25 Oct 2019].

2 Kassebaum NJ, Barber RM, Bhutta ZA, et al. Global, regional, and national levels of maternal mortality, 1990-2015: a systematic analysis for the global burden of disease study 2015. The Lancet 2016;388:1775-812.

3 Gizelis T-I, Karim S, Østby G, et al. Maternal health care in the time of Ebola: a Mixed-Method exploration of the impact of the epidemic on delivery services in Monrovia. World Dev 2017;98:169-78.

4 Lori JR, Rominski SD, Perosky JE, et al. A case series study on the effect of Ebola on facility-based deliveries in rural Liberia. BMC Pregnancy Childbirth 2015;15:254.

5 lyengar P, Kerber K, Howe CJ, et al. Services for mothers and newborns during the Ebola outbreak in liberia: the need for improvement in emergencies. PLoS Curr 2015;7. doi:10.1371/ currents.outbreaks.4ba318308719ac86fbef91f8e56cb66f. [Epub ahead of print: 16 Apr 2015].

6 Camara BS, Delamou A, Diro E, et al. Effect of the 2014/2015 Ebola outbreak on reproductive health services in a rural district of guinea: an ecological study. Trans R Soc Trop Med Hyg 2017;111:22-9.

7 Delamou A, Ayadi AME, Sidibe S, et al. Effect of Ebola virus disease on maternal and child health services in guinea: a retrospective observational cohort study. Lancet Glob Health 2017;5:e448-57.

8 Sochas L, Channon AA, Nam S. Counting indirect crisis-related deaths in the context of a low-resilience health system: the case of maternal and neonatal health during the Ebola epidemic in Sierra Leone. Health Policy Plan 2017;32:iii32-9.

9 Wagenaar BH, Augusto O, Beste J, et al. The 2014-2015 Ebola virus disease outbreak and primary healthcare delivery in Liberia: timeseries analyses for 2010-2016. PLoS Med 2018;15:e1002508.

10 Shannon FQ, Horace-Kwemi E, Najjemba R, et al. Effects of the 2014 Ebola outbreak on antenatal care and delivery outcomes in Liberia: a nationwide analysis. Public Health Action 2017;7:88-93.

11 Quaglio G, Pizzol D, Bome D, et al. Maintaining maternal and child health services during the Ebola outbreak: experience from Pujehun, Sierra Leone. PLoS Curr 2016;8. doi:10.1371/currents.outbreaks. d67aea257f572201f835772d7f188ba5. [Epub ahead of print: 02 Jun 2016].

12 Caulker VML, Mishra S, van Griensven J, et al. Life goes on: the resilience of maternal primary care during the Ebola outbreak in rural Sierra Leone. Public Health Action 2017;7:40-6.

13 Jones SA, Gopalakrishnan S, Ameh CA, et al. 'Women and babies are dying but not of Ebola': the effect of the Ebola virus epidemic on the availability, uptake and outcomes of maternal and newborn health services in Sierra Leone. BMJ Glob Health 2016;1:e000065.

14 WHO. Maternal mortality: key facts, 2018. Available: http://www. who.int/news-room/fact-sheets/detail/maternal-mortality [Accessed 25 Oct 2019].

15 Jacobs B, Ir P, Bigdeli M, et al. Addressing access barriers to health services: an analytical framework for selecting appropriate interventions in low-income Asian countries. Health Policy Plan 2012;27:288-300.

16 Ensor T, Cooper S. Overcoming barriers to health service access: influencing the demand side. Health Policy Plan 2004;19:69-79.

17 Peters DH, Garg A, Bloom G, et al. Poverty and access to health care in developing countries. Ann N Y Acad Sci 2008;1136:161-71.

18 Levesque J-F, Harris MF, Russell G. Patient-Centred access to health care: conceptualising access at the interface of health systems and populations. Int J Equity Health 2013;12:18.

19 Moher D, Liberati A, Tetzlaff J, et al. Preferred reporting items for systematic reviews and meta-analyses: the PRISMA statement. PLoS Med 2009;6:b2535. 
20 Bell SA, Munro-Kramer ML, Eisenberg MC, et al. "Ebola kills generations": Qualitative discussions with Liberian healthcare providers. Midwifery 2017;45:44-9.

21 Evans DK, Goldstein M, Popova A. Health-Care worker mortality and the legacy of the Ebola epidemic. Lancet Glob Health 2015;3:e439-40.

22 Brolin Ribacke KJ, van Duinen AJ, Nordenstedt H, et al. The impact of the West Africa Ebola outbreak on obstetric health care in Sierra Leone. PLoS One 2016;11:e0150080.

23 Drevin G, Mölsted Alvesson H, van Duinen A, et al. "For this one, let me take the risk": why surgical staff continued to perform caesarean sections during the 2014-2016 Ebola epidemic in Sierra Leone. BMJ Glob Health 2019;4:e001361.

24 Barden-O'Fallon J, Barry M, Brodish P, et al. Rapid assessment of Ebola-related implications for reproductive, maternal, newborn and child health service delivery and utilisation in guinea. PLOS Current Outbreaks 2015;7.

25 Dynes MM, Miller L, Sam T, et al. Perceptions of the risk for Ebola and health facility use among health workers and pregnant and lactating women--Kenema District, Sierra Leone, September 2014. MMWR Morb Mortal Wkly Rep 2015;63:1226-7.

26 Jones S, Ameh C VSO. Exploring the impact of the Ebola outbreak on routine maternal health services in Sierra Leone, 2015. Available: https://www.vsointernational.org/sites/default/files/ VSO \%20Sierroa\%20Leone\%20-\%20Impact\%20of\%20Ebola.pdf [Accessed 30 Jun 2020].

27 UNFPA. Rapid assessment of Ebola impact on reproductive health services and service seeking behaviour in Sierra Leone, 2015. Available: https://reliefweb.int/sites/reliefweb.int/files/resources/ UNFPA\%20study\%20_synthesis_March\%2025_final.pdf [Accessed 30 Jun 2020].

28 Delamou A, Sidibé S, El Ayadi AM, et al. Maternal and child health services in the context of the Ebola virus disease: health care workers' knowledge, attitudes and practices in rural guinea. Afr J Reprod Health 2017;21:104-13.

29 Erland E, Dahl B. Midwives' experiences of caring for pregnant women admitted to Ebola centres in Sierra Leone. Midwifery 2017;55:23-8.

30 Jones S, Sam B, Bull F, et al. 'Even when you are afraid, you stay': provision of maternity care during the Ebola virus epidemic: a qualitative study. Midwifery 2017;52:19-26.

31 Jones T, Ho L, Kun KK, et al. Rebuilding people-centred maternal health services in post-Ebola Liberia through participatory action research. Glob Public Health 2018;13:1650-69.

32 Black BO. Obstetrics in the time of Ebola: challenges and dilemmas in providing lifesaving care during a deadly epidemic. BJOG 2015;122:284-6.

33 Ministry of Social Welfare, Gender and Children's Affairs, UN Women, Oxfam. Report of the multisector impact assessment of gender dimensions of the Ebola virus disease (EVD) in Sierra Leone, 2014. Available: https://awdf.org/wp-content/uploads/FINALREPORT-OF-THE-Multi-Sectoral-GENDER-Impact-Assessment Launchedon_24th-Feb-2015_Family_kingdom_Resort.pdf [Accessed 30 Jun 2020].

34 McQuilkin PA, Udhayashankar K, Niescierenko M, et al. Health-Care access during the Ebola virus epidemic in Liberia. Am J Trop Med Hyg 2017;97:931-6.

35 Miller NP, Milsom P, Johnson G, et al. Community health workers during the Ebola outbreak in guinea, Liberia, and Sierra Leone. $J$ Glob Health 2018;8:020601.

36 Elston JWT, Moosa AJ, Moses F, et al. Impact of the Ebola outbreak on health systems and population health in Sierra Leone. J Public Health 2016;38:673-8.

37 Shultz JM, Cooper JL, Baingana F, et al. The role of fear-related behaviors in the 2013-2016 West Africa Ebola virus disease outbreak. Curr Psychiatry Rep 2016;18:104.

38 Strong A, Schwartz DA. Sociocultural aspects of risk to pregnant women during the 2013-2015 multinational Ebola virus outbreak in West Africa. Health Care Women Int 2016;37:922-42.

39 Elston JWT, Cartwright C, Ndumbi P, et al. The health impact of the 2014-15 Ebola outbreak. Public Health 2017;143:60-70.
40 Raven J, Wurie H, Witter S. Health workers' experiences of coping with the Ebola epidemic in Sierra Leone's health system: a qualitative study. BMC Health Serv Res 2018;18:251.

41 O'Leary A, Jalloh MF, Neria Y. Fear and culture: contextualising mental health impact of the 2014-2016 Ebola epidemic in West Africa. BMJ Glob Health 2018;3:e000924.

42 Grinnell M, Dixon MG, Patton M, et al. Ebola Virus Disease in Health Care Workers--Guinea, 2014. MMWR Morb Mortal Wkly Rep 2015;64:1083-7.

43 McMahon SA, Ho LS, Brown H, et al. Healthcare providers on the frontlines: a qualitative investigation of the social and emotional impact of delivering health services during Sierra Leone's Ebola epidemic. Health Policy Plan 2016;31:1232-9.

44 Sow S, Desclaux A, Taverne B. Ebola in guinea: forms of stigmatization of surviving health care workers. Bull Soc Pathol Exot 2016;109:309-13.

45 CDC. 2014-2016 Ebola outbreak in West Africa, 2019. Available: https://www.cdc.gov/vhf/ebola/history/2014-2016-outbreak/index. html\# ftn4 [Accessed Mar 2020].

46 WHO. Health worker Ebola infections in guinea, Liberia, and Sierra Leone, 2015. Available: https://apps.who.int/iris/bitstream/ handle/10665/171823/WHO_EVD_SDS_REPORT_2015.1_eng.pdf; jsessionid $=8786 \mathrm{~B} 75 \mathrm{E} 6 \mathrm{ED0BA3ECAC237306D3D95D6}$ ? sequence $=1$ [Accessed Mar 2020].

47 Frieden TR, Damon IK. Ebola in West Africa--CDC's Role in Epidemic Detection, Control, and Prevention. Emerg Infect Dis 2015;21:1897-905

48 Hageman JC, Hazim C, Wilson K, et al. Infection Prevention and Control for Ebola in Health Care Settings - West Africa and United States. MMWR Suppl 2016;65:50-6.

49 WHO. Interim infection prevention and control guidance for care of patients with suspected or confirmed filovirus haemorrhagic fever in health-care settings, with focus on Ebola, 2014. Available: http:// www.euro.who.int/ data/assets/pdf file/0005/268772/InterimInfection-Prevention-and-Control-Guidance-for-Care-of-Patientswith-Suspected-or-Confirmed-Filovirus-Haemorrhagic-Fever-inHealth-Care-Settings,-with-Focus-on-Ebola-Eng.pdf [Accessed Oct 2019].

50 Wilkinson A, Leach M. Briefing: Ebola-myths, realities, and structural violence. Afr Aff 2015;114:136-48.

51 Blair RA, Morse BS, Tsai LL. Public health and public trust: survey evidence from the Ebola virus disease epidemic in Liberia. Soc Sci Med 2017:172:89-97.

52 Pellecchia U, Crestani R, Decroo T, et al. Social consequences of Ebola containment measures in Liberia. PLoS One 2015:10:e0143036.

53 Li W, Jalloh MF, Bunnell R, et al. Public Confidence in the Health Care System 1 Year After the Start of the Ebola Virus Disease Outbreak - Sierra Leone, July 2015. MMWR Morb Mortal Wkly Rep 2016;65:538-42.

54 Shoman H, Karafillakis E, Rawaf S. The link between the West African Ebola outbreak and health systems in guinea, Liberia and Sierra Leone: a systematic review. Global Health 2017;13:1.

55 WHO. Everybody's business: strengthening health systems to improve health outcomes: WHO's framework for action, 2007. Available: http://www.who.int/healthsystems/strategy/everybodys business.pdf?ua $=1$ [Accessed 25 Oct 2019].

56 Person B, Sy F, Holton K, et al. Fear and stigma: the epidemic within the SARS outbreak. Emerg Infect Dis 2004;10:358-63.

57 Rugarabamu S, Mboera L, Rweyemamu M, et al. Forty-Two years of responding to Ebola virus outbreaks in sub-Saharan Africa: a review. BMJ Glob Health 2020;5:e00195:e001955.

58 Palagyi A, Marais BJ, Abimbola S, et al. Health system preparedness for emerging infectious diseases: a synthesis of the literature. Glob Public Health 2019;14:1847-68.

59 Roberton T, Carter ED, Chou VB, et al. Early estimates of the indirect effects of the COVID-19 pandemic on maternal and child mortality in low-income and middle-income countries: a modelling study. Lancet Glob Health 2020;8:e901-8. 